\title{
Abnormal Glycosylation of Red Cell Membrane Band 3 in the Congenital Disorder of Glycosylation Ig
}

\author{
EWA ZDEBSKA, BRIGITTE BADER-MEUNIER, PIERRE-OLIVIER SCHISCHMANOFF, \\ THIERRY DUPRÉ, NATHALIE SETA, GIL TCHERNIA, JERZY KOŚCIELAK, AND \\ JEAN DELAUNAY
}

\begin{abstract}
Department of Biochemistry, Institute of Hematology and Blood Transfusion, 00-957 Warsaw, Poland
[E.Z., J.K.]; Service de Biochimie I [P.-O.S.], Service de Pédiatrie Générale [B.B.-M.], Service

d'Hématologie, d'Immunologie et de Cytogénétique [G.T., J.D.], Hôpital de Bicêtre, AP-HP, Faculté de Médecine Paris-Sud, 94275 Le Kremlin-Bicêtre, France; INSERM U 473, 94276 Le Kremlin-Bicêtre,

France [G.T., J.D.]; Service de Biochimie A, Hôpital Bichat, AP-HP, 75877 Paris France [T.D., N.S.]
\end{abstract}

\section{ABSTRACT}

A description is provided of the clinical presentation in an infant of the recently described congenital disorder of glycosylation type $\mathrm{Ig}$, and the changes affecting glycosylation of red cell membrane band 3, the anion exchanger. It has been shown that the condition stems from a homozygous mutation within the human ortholog of yeast ALG12 gene, which encodes a dolicholP-mannose:Man GlcNAc $_{2}$-PP-dolichol $\alpha, 1-6$ mannosyltransferase of the endoplasmic reticulum. The clinical phenotype included prominent central and peripheral manifestations in the CNS. Although the infant studied had no anemia, band 3 abnormally separated into two fractions upon electrophoresis. The chemical composition of the glycans of both fractions was analyzed in detail. The fraction with low electrophoretic mobility was moderately hypoglycosylated (by 27\%) and its mannose content was normal. The fraction with high electrophoretic mobility was deeply carbohydrate deficient (by 64\%) and had $1 \mathrm{~mol}$ mannose in excess but only three residues of $\mathrm{N}$-acetylglucosamine. Glycophorin A was hypoglycosylated with respect to $O$-linked glycans. Glycosphingolipids of red cells were normal. We suggest that the incomplete biosynthesis of the $N$-linked glycan of band 3 was largely caused by the persistence of the 3-linked mannose residue on the 6-mannose arm of the trimannosyl moiety of the glycoprotein. It is remarkable that the changes recorded in band 3 have no clinical consequences. Band 3 alteration might serve as an additional indicator (some serum $\mathrm{N}$-glycoproteins of hepatic origin are also indicative) of the congenital disorder of glycosylation type Ig. (Pediatr Res 54: 224-229, 2003)

\section{Abbreviations}

ALG12, gene encoding the dolichyl-Pmannose:Man7GlcNAc2-PP-dolichol mannosyltransferase of the endoplasmic reticulum

CDG, congenital disorder of glycosylation

LLO, lipid-linked oligosaccharide

Gal, galactose

GalNAc, $N$-acetylgalactosamine

GIcNAc, $N$-acetylglucosamine

Man, mannose

$\mathbf{P}$, phosphate

PP, pyrophosphate
CDG designates a group of rare inherited diseases of metabolism characterized by a variety of glycosylation defects of glycoproteins that are involved in different metabolic functions. CDG I comprises all defects in the assembly of the dolichol-linked glycan and its transfer to the protein, whereas

Received September 3, 2002; accepted November 12, 2002.

Correspondence: Jean Delaunay, Service d'Hématologie, d'Immunologie et de Cytogénétique, Hôpital de Bicêtre, 78 rue du Général-Leclerc; 94275 Le Kremlin-Bicêtre; France; e-mail: delaunay@kb.inserm.fr

Supported by INSERM U473 and the INSERM/AFM (project number 4MR09F).

DOI: 10.1203/01.PDR.0000072327.55955.F7
CDG II refers to defects in the processing of the protein-bound glycans. Their clinical picture is severe and associated with multisystemic lesions, particularly central and peripheral nervous system deficiencies. Serum $N$-glycoproteins of hepatic origin are abnormally glycosylated.

Thus far, six types of CDG I have been identified and characterized on a molecular basis: i) CDG Ia, which accounts for $80 \%$ of CDG I cases as presently known, is associated with deficient phosphomannomutase, encoded by the PMM2 gene (1); ii) CDG Ib is associated with deficient phosphomannose isomerase, encoded by the MPI gene (2); iii) CDG Ic with deficient glucosyltransferase, encoded by the $h A L G 6$ gene (3); 
iv) CDG Id, with deficient mannosyltransferase, encoded by the $h A L G 3$ gene (4); v) CDG Ie, with deficient dolicholphosphate-mannose synthase-1, encoded by the DPM1 gene (5); and vi) CDG If, with deficient Lec35 protein, encoded by the Lec35 gene (6). CDG I cases for which the genetic origins remain unknown are defined as CDG subtype Ix. Their clinical presentations are heterogeneous.

We recently described the novel CDG Ig, involving still another endoplasmic reticulum enzyme- a mannosyltransferase. The latter is encoded by the human ortholog of yeast gene $A L G 12$ (7). We report here the clinical presentation and the altered glycosylation of red cell membrane band 3 in the first patient described with this condition. It is odd that there were no gross hematological signs among so many manifestations and despite pronounced alterations of the band 3 glycan moiety. Previously, aberrant glycosylation of band 3 was described in one patient with a CDG II (8), and abnormalities of both band 3 and glycophorin A were reported in three patients with CDG Ia (9).

\section{METHODS}

Patient. The investigation was undertaken after informed consent of the parents was obtained.

The patient is a Tunisian infant. She is the third child of consanguineous parents. Neonatal weak suckling and hypotonia were the first clinical manifestations. Facial dysmorphic features (prominent forehead, large ears, thin upper lip) were also present. During the clinical course, severe psychomotor retardation appeared as the main symptom. At the age of 3 , the girl was unable to sit and walk and needed enteral feeding with a percutaneous endoscopic gastrostomy. Failure to thrive and strabismus were noted. The concentration of serum electrolytes and creatinine, and liver function were normal. Blood cell count revealed monocytosis ranging from 1 to $2.5 \times 10^{9} / \mathrm{L}$, and normal leukocyte and platelet counts. Red cell indices appeared essentially normal (Hb: $11.6 \mathrm{~g} / \mathrm{dL}$; mean corpuscular volume: $75 \mathrm{fL}$; mean corpuscular $\mathrm{Hb}$ concentration: $32 \mathrm{~g} / \mathrm{dL}$; mean corpuscular $\mathrm{Hb}: 24 \mathrm{pg} / \mathrm{L}$ ). Bilirubinemia was normal. Some coagulation factors were decreased, including factor XI (26\%), antithrombin $(33 \%)$, protein $\mathrm{C}(52 \%)$, and protein $\mathrm{S}$ $(37 \%)$. Serum $\operatorname{IgG}$ was reduced $(2 \mathrm{~g} / \mathrm{L}$; normal, $>4 \mathrm{~g} / \mathrm{L})$. The serum blood serum contained no unusual anti-red cell antibodies according to the Coombs' test using blood group O cells.

At 6 mo of age, a diagnostic procedure was performed. The Western blot profile, as well as isoelectric focusing of transferrin, showed a hypoglycosylation pattern characteristic of CDG. Cranial magnetic resonance imaging was normal. Constitutional karyotype showed no abnormalities. Amino acids and organic acids in the urine were normal. Nevertheless, phosphomannomutase and phosphomannose isomerase activities, known to be reduced in CDG Ia and Ib, respectively, were normal in the patient's leukocytes and cultured fibroblasts. However, skin biopsy fibroblasts were deficient in their capacity to add the eighth Man residue onto the LLO precursor.

We found that the cDNA corresponding to the human ortholog of the yeast $A L G 12$ gene carried a base substitution: $\mathrm{T} 571 \mathrm{G}$ in the homozygous state. One would expect the protein product, the dolichol-P-Man:Man ${ }_{7} \mathrm{GlcNAc}_{2}-\mathrm{PP}$-dolichol $\alpha$ 1-6 mannosyltransferase, to show the amino acid substitution F142V. The pathologic phenotype of the patient's fibroblasts was largely normalized upon transfection with the wild-type gene. Accordingly, this change was considered the cause of a novel disease, which was termed CDG Ig (7).

Methods. Red cell membrane proteins were analyzed using PAGE in the presence of SDS $(10,11)$.

Carbohydrate molar composition of glycoproteins was determined as previously described (12). The method involves simultaneous quantification of carbohydrate and protein contents of glycoproteins separated by SDS-PAGE and thereafter electroblotted onto polyvinyl difluoride membranes. Bands of the glycoproteins under study were excised and sequentially hydrolyzed in situ with $0.2 \mathrm{M}$ trifluoric acid, $2 \mathrm{M}$ trifluoric acid, and $6 \mathrm{M} \mathrm{HCl}$ to release sialic acid, neutral sugars with hexosamines, and amino acids. The carbohydrates were analyzed by high $\mathrm{pH}$ anion exchange chromatography with pulsed amperometric detection using the Dionex system (Dionex Corporation, Sunnyvale, California, U.S.A.) and PA-1 column (13), and protein was determined as amino acids by the fluorescamine method (14).

Glycophorin A was analyzed by the same method. Before being subjected to electrophoresis, it was purified by extraction with aqueous phenol (15). Purification was followed by dialysis.

Oligoglycosylceramides were extracted from the lyophilized erythrocyte membranes successively with $5 \mathrm{~mL}$ portions of chloroform-methanol 1:2 and 2:1 by volume, respectively, and thereafter fractionated to pure compounds as described previously (13). Polyglycosylceramides were extracted from the insoluble residue of the organic solvent-extracted membranes after a preliminary acetylation step (16). Both oligo- and polyglycosylceramides were quantified as carbohydrates and sphingosine after hydrolysis of individual glycosphingolipids with $2 \mathrm{M}$ trifluoroacetic acid for $4 \mathrm{~h}$ at $100^{\circ} \mathrm{C}$.

\section{RESULTS}

Electrophoresis of serum glycoproteins and enzyme activities. In comparison with controls, the patient's serum exhibited the presence of two additional bands of lower molecular weight on transferrin Western blot profile (not shown). The isoelectrofocusing pattern showed a marked elevation of the tri-, di-, mono-, and asialotransferrin fraction. A generalized glycosylation defect was confirmed by Western blot patterns of $\alpha$-1-antitrypsin, $\alpha$-1-acid glycoprotein, and haptoglobin (not shown). Taken together, these results were characteristic of CDG I patients. Normal activities of phosphomannomutase and phosphomannose isomerase in fibroblasts as well as in leukocytes from the patient and her parents ruled out CDG Ia and CDG Ib (7).

Electrophoresis of red cell membrane proteins. Band 3 was markedly altered. It consisted of two peaks instead of the normal single broad peak, suggesting a glycosylation abnormality. The intensity of the peak with low electrophoretic mobility (LM) was slightly lighter as compared with the peak displaying the high mobility (HM). It was also slightly larger 
than normal (Fig. 1). The upper edge of the LM fraction was smoother and shifted upward. The lower edge of the HM fraction had a normal aspect but was shifted downward. Densitometric quantification of Coomassie blue-stained gel indicated a normal surface area. A profile from a patient with congenital dyserythropoietic anemia (CDA II) is presented as a distinct abnormality of band 3 glycolylation (Fig. 1).

Chemical analysis of band 3 glycan moiety. The two fractions of band 3 were separately analyzed for carbohydrate molar composition (Table 1). The LM fraction exhibited a significantly decreased number of carbohydrate residues per mole but had a normal level of three residues of Man. The HM fraction was deeply deficient in carbohydrates and contained about 1 mol Man in excess. Its content of GlcNAc was close to three residues. These results, as well as the known order of addition of GlcNAc residues to the two branches of the trimannosyl moiety of $\mathrm{N}$-glycans with the 3-Man arm being substituted first (for review, see Ref. 17), suggest that the core portion of the HM fraction had the structure depicted in Figure 2.

In normal controls, there was also a difference between the leading and trailing edges of band 3 but it amounted to only several sugar residues. In addition, Man contents of the two fractions were identical (not shown). We cannot explain the higher than expected amount of Gal relative to GlcNAc in HM fraction. A small amount of GalNAc occurred in all preparations of band 3 , and is probably an impurity. In blood group A individuals, there is an additional amount of GalNAc that is a part of blood group A epitope (for review, see Ref. 18).

Chemical analysis of glycophorin A glycan moiety. We failed to observe any gross change in the mobility of glycophorin A in SDS-PAGE (not shown). This glycoprotein has normally about $12 \mathrm{O}$-linked glycans, as shown by its content of GalNAc (15). This number is preserved in glycophorin A of the patient (Table 2). The $O$-linked glycans of the patient's glycophorin A were, however, hypoglycosylated, because its contents of Gal and $N$-acetylneuraminic acid were significantly decreased. Gross abnormalities in the amounts of GlcNAc and Man, the components of the single $N$-linked glycan of glycophorin A, were not observed, although the amounts of the two sugars were on the low and high side of normal values, respectively.

Chemical analysis of glycosphingolipid glycan moiety. Contents of most glycosphingolipids in patient's erythrocytes, including polyglycosylceramides, were normal (Table 3). The polyglycosylceramides also had the normal carbohydrate molar composition, although a polylactosamino type glycan very similar to that of band 3 was present (for review, see Ref. 18).

\section{DISCUSSION}

Abnormal electrophoretic profile of band 3. The present case is probably the first example of a clear separation of band 3 into two subfractions of different electrophoretic mobility in

\section{CDA II CDG 1g}
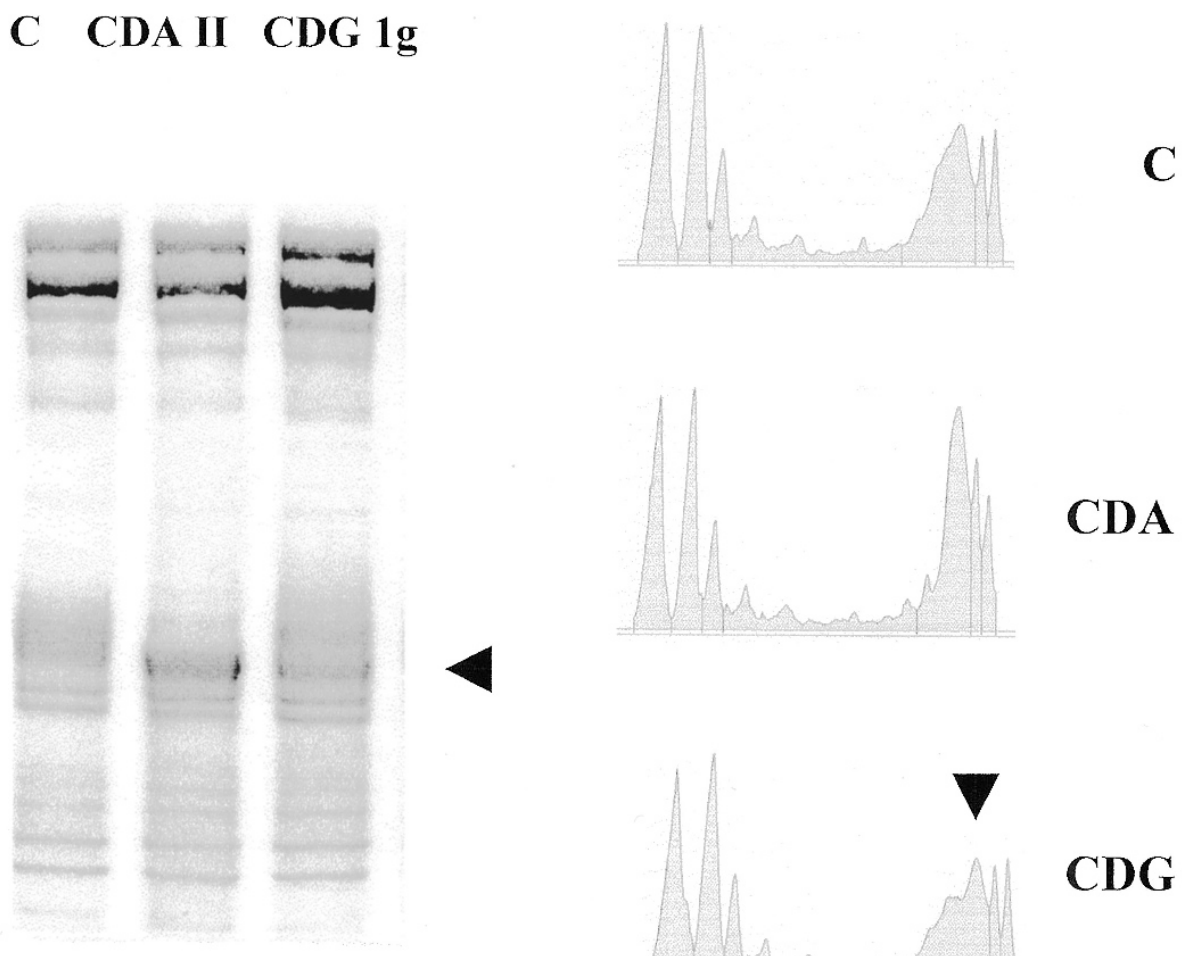

\section{CDA II}

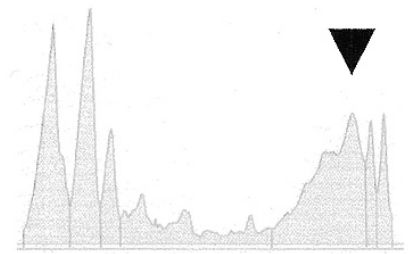

\section{CDG 19}

Figure 1. SDS-PAGE of red cell membrane proteins. Left panel: Arrowhead indicates band 3. Right panel: C (top) is the normal control. CDA II (middle) is the control with congenital dyserythropoietic anemia, chosen to illustrate another marked, yet distinct, abnormality of band 3 (band 3 was narrower and had a higher electrophoretic mobility). CDG Ig (bottom) is from the patient under study. Band 3 was wider (arrowhead) and was duplicated into an upper fraction (low electric mobility) and a lower fraction (higher electrophoretic mobility [HM]). The lower edge of the HM fraction was lower (as in CDA II) than that in the normal control. Scanning showed the amount of band 3 was normal in CDG Ig (as in CDA II). 
GLYCANS OF RED CELL BAND 3 IN CDG IG

Table 1. Carbohydrate molar composition of band 3

\begin{tabular}{|c|c|c|c|c|c|c|c|}
\hline Material analyzed & Fuc & GalNAc & GlcNAc & Gal & Man & NeuAc & Total CHO $(\%)$ \\
\hline \multicolumn{8}{|l|}{ Band 3, CDG Ig } \\
\hline LM fraction (mol/mol) & 2.5 & 0.4 & 11.3 & 8.6 & 2.9 & 0.4 & $26.1(5.5)$ \\
\hline HM fraction $(\mathrm{mol} / \mathrm{mol})$ & 0.5 & 0.7 & 3.4 & 3.4 & 4.3 & 0.5 & $12.8(2.7)$ \\
\hline$\pm \mathrm{SD}(\mathrm{mol} / \mathrm{mol})$ & 0.5 & 0.5 & 0.8 & 1.4 & 0.3 & 0.5 & $1.1(0.2)$ \\
\hline
\end{tabular}

Each monosaccharide species was expressed as moles per mole of protein. The most salient features appear in bold type. CHO, carbohydrate.

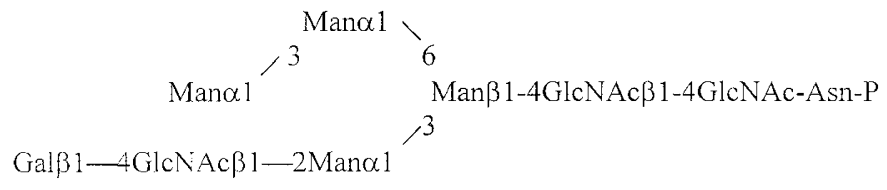

Figure 2. Proposed structure of $N$-linked glycan of HM fraction.

a condition with aberrant glycosylation (for review, see Ref. 19). The alteration was very different from that observed in CDA II, producing another dramatically abnormal pattern of band $3(20,21)$. The explanation for the double peak in the presently studied case of CDG should be sought in the sequence and nature of events occurring on the biosynthetic path of glycans from endoplasmic reticulum to the Golgi. A reduced activity of the dolichol-P-Man:Man ${ }_{7}$ GlcNAc $_{2}$-PP-dolichol $\alpha 1-6$ mannosyltransferase of the endoplasmic reticulum results in the production of a curtailed form of LLO with the peripheral $\alpha 1-6$ mannosyl branch missing (7) (Fig. 3A). Nevertheless, this compound is still transferred from dolichol onto protein as $\mathrm{N}$-linked $\mathrm{Glc}_{3} \mathrm{Man}_{7} \mathrm{GlcNAc}_{2}$ oligosaccharide. Such a transfer was reported previously in yeast (22). Surprisingly, nonglucosylated $\mathrm{Man}_{7} \mathrm{GlcNAc}_{2}$ oligosaccharide is also transferred onto protein (7). In addition, the mutated $A L G 12$ gene in the patient is leaky and does not prevent the formation of a normal LLO with nine Man and three glucose residues (7). These three oligosaccharides are transferred onto protein in approximately equimolar proportions.

On its path to the Golgi, the normal $N$-linked glycan is trimmed of all $\alpha 1-2$ Man residues down to a total of five Man residues (Fig. 3B) (23) and in the patient's band 3 to four Man residues, presumably. Both $N$-linked glycans should be good substrates for $N$-acetylglucosaminyltransferase I ( GnT 1), which adds GlcNAc residue to the 3-Man arm of the trimannosyl core (24), thus initiating the first, less complex antenna (25) and at the same time providing a signal for mannosidase II to cleave two mannosyl residues from the 6-Man arm of the core. In the case of the normal $N$-linked glycan of the complex type, the exposed 6-Man arm of the core becomes a substrate for $\mathrm{N}$-acetylglucosaminyltransferase II (GnT II) (for review, see Ref. 17), thereby initiating biosynthesis of the second, a more complex antenna of band 3 (25). It is very probable, however, that mannosidase II is unable to cleave the single peripheral Man-3 linked to the 6-Man arm of the core of the patient's band 3 because mannosidases II from various animal and plant sources hydrolyze the peripheral 6-linked Man (6Man) before the peripheral 3-linked Man (3-Man) (26, 27). A recent proposal for the reaction mechanism suggests that only after the cleavage of the peripheral 6-Man is the peripheral 3-Man brought into the active site cavity of the enzyme (28).
Thus, in the absence of the peripheral 6-Man in the patient, the hydrolysis of the peripheral 3-Man may well be hampered. It is, however, possible that the peripheral 3-Man is hydrolyzed by mannosidase II even in the absence of the peripheral 6-Man, but with a lower efficiency. In such a situation, only a part of the peripheral 3-Man would be cleaved, thus providing the substrate for GnT II, in addition to that supplied by the leaky, mutated $A L G 12$ gene. In conclusion, we propose that LM fraction of band 3 resulted from a portion of the protein that was initially glycosylated in the endoplasmic reticulum with a normal LLO, whereas the HM fraction resulted from another portion initially glycosylated with $\mathrm{Glc}_{3} \mathrm{Man}_{7} \mathrm{GlcNAc}_{2}$ oligosaccharide or nonglucosylated $\mathrm{Man}_{7} \mathrm{GlcNAc}_{2}$ oligosaccharide or both. We consider it more likely, however, that $N$-linked glycan of HM fraction of band 3 originated from LLO with a more physiologic $\mathrm{Glc}_{3} \mathrm{Man}_{7} \mathrm{GlcNAc}_{2}$ structure. It appears that SDS-PAGE of band 3 glycan moiety constitutes a biochemical stigmata for the diagnosis of this CDG on par with transferrin isoelectric focusing or Western blotting of a variety of proteins.

Glycophorin A. Glycophorin A of the present CDG patient shows hypoglycosylation of $O$-linked chains. In contrast, this glycoprotein is partly unglycosylated (nonglycosylated) in CDG Ia (9) and in several patients with CDA I and CDA II (15, $29,30)$. In all these cases, glycosylation of band 3 was reduced. In subjects with the so-called En (-) phenotype, glycophorin A is largely missing but band 3 is overglycosylated (for review, see Ref. 31). Conversely, when the amount of glycophorin A is increased, the size of band 3 glycan is reduced. Aberrant glycosylation of glycophorin A in many diverse conditions affecting band 3 is difficult to rationalize, thus raising the issue of their partnership in biosynthesis.

Glycosphingolipids. Normal contents of most glycosphingolipids, including polyglycosylceramides, in red cells of the patient sharply separate CDG Ig from CDA I-III, because, in the latter group of diseases, lactotriaosylceramide, neotetraosylceramide, and polyglycosylceramides are invariably elevated $(29,32,33)$. Polyglycosylceramides are, in addition, hypoglycosylated $(29,34)$. It has been proposed that the increased content of polyglycosylceramides in erythrocytes of CDA II patients is of a compensatory type because band 3 and polyglycosylceramides have glycans of the same polylactosamino type that are synthesized, presumably, by the same glycosyltransferases (for review, see Ref. 35). Thus, when the amount of protein-bound substrate is diminished, the enzymes overglycosylate ceramides. This explanation should not apply to the present patient, in whom the glycosylation of band 3 was reduced by about $50 \%$, yet the content and glycosylation of polyglycosylceramides were normal. 
Table 2. Carbohydrate (CHO) molar composition of glycophorin A

\begin{tabular}{|c|c|c|c|c|c|c|c|}
\hline Material analyzed & Fuc & GalNAc & GlcNAc & Gal & Man & NeuAc & $\begin{array}{c}\text { Total } \\
\text { CHO }(\%)\end{array}$ \\
\hline Glycophorin A, CDG Ig (mol/mol) & 1.6 & 11.7 & 5.4 & 17.7 & 3.5 & 14.5 & $\mathbf{5 4 . 4}(39.1)$ \\
\hline Glycophorin A, normal adults, $(n=9)(\mathrm{mol} / \mathrm{mol})$ & 2.9 & 12.2 & 6.8 & 23.2 & 3.0 & 21.2 & $69.3(50.5)$ \\
\hline$\pm \mathrm{SD}(\mathrm{mol} / \mathrm{mol})$ & 0.6 & 1.2 & 0.8 & 1.09 & 0.2 & 1.2 & $1.8(1.4)$ \\
\hline
\end{tabular}

Each monosaccharide species was expressed as moles per mole of protein. The most salient features appear in bold type.

Table 3a. Contents of glycosylceramides in erythrocyte membranes: oligoglycosylceramides

\begin{tabular}{|c|c|c|c|c|c|c|}
\hline Material analyzed & GlcCer & LacCer & Lc3Cer & Gb3Cer & Gb4Cer & nLc4Cer \\
\hline Oligoglycosylceramides, CDG 1g & 0.5 & 3.5 & 0.1 & 2.5 & 9.1 & 0.01 \\
\hline Oligoglycosylceramides, normal adults $(n=15)$ & 0.8 & 3.4 & 0.1 & 3.1 & 11.6 & 0.006 \\
\hline$\pm \mathrm{SD}$ & 0.07 & 0.2 & 0.05 & 0.3 & 1.2 & 0.004 \\
\hline
\end{tabular}

Measurements expressed as nanomoles per mg membrane proteins.

Table 3b. Contents of glycosylceramides in erythrocyte membranes: polyglycosylceramides (PGC)

\begin{tabular}{lrr}
\hline \multicolumn{1}{c}{ Material analyzed } & $\mathrm{a}$ & $\mathrm{b}$ \\
\hline PGC, CDG 1g & 35.6 & 29.4 \\
PGC, normal adults $(n=9)$ & 35.6 & 33.8 \\
\pm SD & 3.1 & 2.6 \\
\hline
\end{tabular}

Measurements expressed as nanomoles per $100 \mathrm{mg}$ membrane proteins (a), or as the sum of all sugar residues per mole of PGC (b).

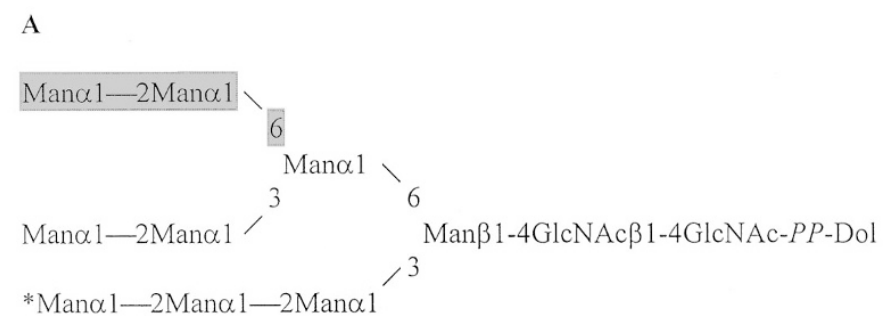

B

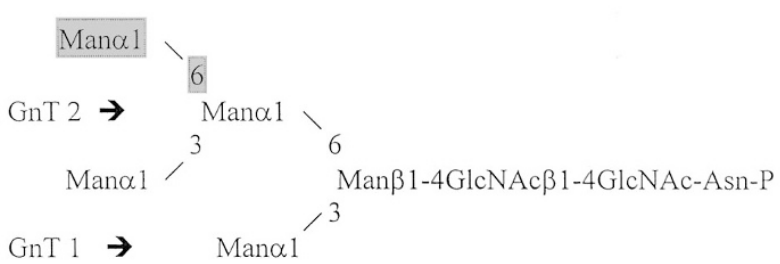

Figure 3. Structures of LLO $(A)$ and of $N$-linked glycan in the middle Golgi (B). In both $A$ and $B$, the shaded areas depict structures that should be missing in HM fraction. The asterisk marks the mannosyl residue to which the triglucosyl tag is attached. Arrows mark acceptor Man residues for GnT 1 and GnT 2.

CDG Ig and CDA II display opposite statuses in other respects as well. In keeping with the electrophoretic aspect of band 3 in CDA II (see above), the latter protein shows dramatic glycosylation changes (for review, see Ref. 35). However, several genes encoding glycan metabolism enzymes had been excluded (36). The responsible gene for CDA II has been mapped (37), but remains unidentified. Would CDA II nonetheless stem from a glycan metabolism gene, CDA II would stand in sheer contrast with CDG Ig. The former is restricted to the red cells whereas the latter is associated with multifaceted clinical manifestations. Why should the glycan alteration of band 3 be deleterious in CDA II, or at least be associated with dyserythropoiesis and fragile mature red cells, and remain innocuous in CDG Ig erythroid precursors and mature erythrocytes?

Apart from this study, glycosylation abnormalities of band 3 were reported only in CDG Ia (9) and CDG IIa (8). No hematological signs were recorded. In the first instance, the abnormalities were due to a deficiency of the enzyme that supplies Man-1-phosphate for the biosynthesis of GDP-Man. Inadequate supply of GDP-Man resulted in an impaired biosynthesis of LLO and, consequently, of $N$-linked glycoproteins. Some of them, like band 3, were hypoglycosylated (9), whereas others, like transferrin, were partially or fully unglycosylated $(38,39)$. Recently, we have found an alteration of electrophoretic mobility of band 3 of red cells in a patient with CDG II. The patient was again devoid of hematological symptoms (unpublished data). In patients with CDG IIa, the observed hypoglycosylation of band 3 is due to a deficiency of $\mathrm{N}$-acetylglucosaminyl transferase II, the enzyme that transfers GlcNAc to the 6-arm of the trimannosyl core of the glycoprotein, thus initiating the biosynthesis of its second antenna (8).

\section{CONCLUSION}

In the present CDG Ig, band 3 glycosylation abnormalities are easy to show, based on SDS-PAGE. If such an observation was to be generalized in CDG, then band 3 would become a mirror of a general glycosylation defect on par with the glycosylation defect of serum $\mathrm{N}$-glycoproteins of hepatic origin. Misglycosylation of band 3 also asks the question why it fails to induce any changes in the red cell physiology. We proposed an explanation for the misglycosylation of band 3 in CDG Ig.

Acknowledgments. The authors thank Ms. M. Dehan for her sharp editing of the manuscript.

\section{REFERENCES}

1. Jaeken J, Matthijs G 2001 Congenital disorders of glycosylation. Annu Rev Genomics Hum Genet 2:129-151

2. de Lonlay P, Cuer M, Vuillaumier-Barrot S, Beaune G, Castelnau P, Kretz M, Durand G, Saudubray JM, Seta N 1999 Hyperinsulinemic hypoglycemia as a presenting sign in phosphomannose isomerase deficiency: a new manifestation of carbohydratedeficient glycoprotein syndrome treatable with mannose. J Pediatr 135:379-383

3. Imbach T, Burda P, Kuhnert P, Wevers RA, Aebi M, Berger EG, Hennet T 1999 A mutation in the human ortholog of the Saccharomyces cerevisiae ALG6 gene causes carbohydrate-deficient glycoprotein syndrome type-Ic. Proc Natl Acad Sci U S A 96:6982-6987 
4. Korner C, Knauer R, Stephani U, Marquardt T, Lehle L, von Figura K 1999 Carbohydrate deficient glycoprotein syndrome type IV: deficiency of dolichyl-PMan:Man(5)GlcNAc(2)-PP-dolichyl mannosyltransferase. EMBO J 18:6816-6822

5. Imbach T, Schenk B, Schollen E, Burda P, Stutz A, Grunewald S, Bailie NM, King MD, Jaeken J, Matthijs G, Berger EG, Aebi M, Hennet T 2000 Deficiency of dolichol-phosphate-mannose synthase-1 causes congenital disorder of glycosylation type Ie. J Clin Invest 105:233-239

6. Schenk B, Imbach T, Frank CG, Grubenmann CE, Raymond GV, Hurvitz H, Raas-Rotschild A, Luder AS, Jaeken J, Berger EG, Matthijs G, Hennet T, Aebi M 2001 MPDU1 mutations underlie a novel human congenital disorder of glycosylation, designated type If. J Clin Invest 108:1687-1695

7. Chantret I, Dupré T, Delenda C, Bucher S, Dancourt J, Barnier A, Charollais A, Héron D, Bader-Meunier B, Danos O, Seta N, Durand G, Oriol R, Codogno P, Moore SE 2002 Congenital disorders of glycosylation type Ig is defined by a deficiency in dolichyl-P-mannose: Man7GlcNAc2-PP-dolichyl mannosyltransferase. J Biol Chem 277:25815-25822

8. Charuk JH, Tan J, Bernnardini M, Haddad S, Reithmeier RA, Jaeken J, Schachter H 1995 Carbohydrate-deficient glycoprotein syndrome type II. An autosomal recessive $\mathrm{N}$-acetylglucosaminyl transferase II deficiency different from typical hereditary erythroblastic multinuclearity, with a positive acidified serum lysis test (HEMPAS). Eur J Biochem 230:797-805

9. Zdebska E, Musielak M, Jaeken J, Kościelak J 2001 Band 3 glycoprotein and glycophorin A from erythrocytes of children with congenital disorder of glycosylation type Ia are underglycosylated. Proteomics 1:269-274

10. Laemmli UK 1970 Cleavage of structural proteins during the assembly of the head of bacteriophage T4. Nature 227:680-685

11. Fairbanks G, Steck TL, Wallach DF 1971 Electrophoresis analysis of the majo polypeptides of the human erythrocyte membrane. Biochemistry 10:2606-2617

12. Zdebska E, Kościelak J 1999 A single sample method for determination of carbohydrate and protein contents of glycoprotein bands separated by sodium dodecyl sulfate polyacrylamide gel electrophoresis. Anal Biochem 275:171-179

13. Zdebska E, Wózniak J, Dzieciatkowska A, Kościelak J 1998 In comparison to progenitor platelets, microparticles are deficient in GpIb-derived carbohydrates, glycerophospholipids, glycosphingolipids and ceramides. Acta Biochim Pol 45:417428

14. Undefriend S, Stein S, Bohlen P Dairman W Leimgruber W, Weigele M 1972 Fluorescamine a reagent for assay of amino acids, peptides, proteins and primary amines in the picomole range. Science 178:871-872

15. Zdebska E, Adamczyk-Popławska M, Kościelak J 2000 Glycophorin A in two patients with congenital dyserythropoietic anaemia type I and type II is partly unglycosylated. Acta Biochim Pol 47:773-779

16. Miller Podraza H, Andersson C, Karlsson KA 1993 New method for the isolation of polyglycosylceramides from human erythrocyte membranes. Biochim Biophys Acta 1168:330-339

17. Schachter $\mathrm{H} 2000$ The joys of HexNAc. The synthesis and function of $\mathrm{N}$-and O-glycan branches. Glycoconj J 17:465-483 (Review)

18. Kościelak J 2001 ABH blood group active glycoconjugates from human red cells Transfus Med. 11:267-279

19. Kościelak J 1995 Diseases of aberrant glycosylation. Acta Biochim Pol 42:1-10

20. Alloisio N, Jaccoud P, Dorléac E, Morlé L, Philippe N, Marguerite G, Bryon PA, Delaunay J 1982 Alterations of globin chain synthesis and of red cell membrane proteins in congenital dyserythropoietic anemia I and II. Pediatr Res 16:1016-1021

21. Delaunay J, Iolascon A 1999 The congenital dyserythropoietic anaemias. Baillieres Best Pract Res Clin Haematol 12:691-705

22. Burda P, Jakob CA, Beinhauer J, Hegemann H, Aebi M 1999 Ordered assembly of the asymmetrically branched lipid-linked oligosaccharide in the endoplasmic reticu- lum is ensured by the substrate specificity of the individual glycosyltransferases. Glycobiology 9:617-625

23. Herscovics A 1999 Importance of glycosidases in mammalian glycoprotein biosynthesis. Biochim Biophys Acta: 1473:96-107

24. Reck F, Springer M, Meinjohanns E, Paulsen H, Brockhausen I, Schachter H 1995 Synthetic substrate analogues for UDP-GlcNAc Man alpha 1-3R beta 1-2-Nacetylglucosaminyltransferase I. Substrate specificity and inhibitors for the enzyme. Glycoconj J 12:747-754

25. Fukuda M, Dell A, Oates JE, Fukuda MN 1984 Structure of branched glycosaminoglycan, the carbohydrate moiety of band 3 isolated from adult human erythrocytes. J Biol Chem 259:8260-8273

26. Altmann F, März L 1995 Processing of asparagine-linked oligosaccharides in insect cells: evidence for a-mannosidase II. Glycoconj J 12:150-155

27. Ren J, Castellino FJ, Bretthauer RK 1997 Purification and properties of alphamannosidase II from Golgi-like membranes of baculovirus-infected Spodoptera frugiperda (IPLB-SF-21AE) cells. Biochem J 324:951-956

28. van den Elsen J, Kuntz D, Rose D 2001 Structure of Golgi $\alpha$-mannosidase II: a target for inhibition of growth and metastasis of cancer cells EMBO J 20:3008-3017

29. Zdebska E, Gołaszewska E, Fabijańska-Mitek J, Schachter H, Shalev H, Tamary H, Sandström H, Wahlin A, Kościelak J 2001 Glycoconjugate abnormalities in patients with congenital dyserythropoietic anaemia type I, II and III. Br J Haematol 114:907913

30. Zdebska E, Mendek-Czajkowska E, Płoski R, Wózniewicz B, Kościelak J 2002 Heterozygosity of CDAN II (HEMPAS) gene may be detected by the analysis of erythrocyte membrane glycoconjugates from healthy carriers. Haematologica 87:126-130

31. Poole J 2000 Red cell antigen on band 3 and glycophorin A. Blood Rev 14:31-43

32. Zdebska E, Wózniewicz B, Adamowicz-Salach A, Kościelak J 2000 Erythrocyte membranes from a patient with congenital dyserythropoietic anaemia type I (CDA I) show identical, although less pronounced, glycoconjugate abnormalities to those from patients with CDA II (HEMPAS). Br J Haematol 110:998-1001

33. Bouhours JF, Bouhours D, Delaunay J 1985 Abnormal fatty acid composition of erythrocyte glycosphin-golipids in congenital dyserythropoietic anemia type II. J Lipid Res 26:435-441

34. Zdebska E, Anselstetter V, Pacuszka T, Krauze A, Chełstowska H, Heimpel H, Kościelak J 1987 Glycolipids and glycopeptides of red cell membranes in congenital dyserythropoietic anaemia type II (CDA II). Br J Haematol 66:385-391

35. Fukuda MN 1999 HEMPAS. Hereditary erythroblastic multinuclearity with positive acidified serum lysis test. Biochim Biophys Acta 1455:231-239

36. Iolascon A, Miraglia del Giudice E, Perrotta S, Granatiero M, Zelante L, Gasparini P 2001997 Exclusion of three candidate genes as determinants of congenital dyserythropoietic anemia Type II (CDA II). Blood 90:4197-4200

37. Gasparini P, Miraglia del Giudice E, Delaunay J, Totaro A, Granatiero M, Melchionda M, Zelante L, Iolascon A 1997 Localization of congenital dyserythropoietic. anemia II (CDA II) locus to chromosome 20 (20q11.2) by genomewide search. Am J Hum Genet 61:1112-1116

38. Wada Y, Nishikawa A, Okamoto N, Inui K, Tsukamoto H, Okada S, Taniguchi N 1992 Structure of serum transferrin in carbohydrate-deficient glycoprotein syndrome. Biochem Biophys Res Commun 189:832-836

39. Yamashita K, Ideo H, Ohkura T, Fukushima K, Yuasa I, Ohno K, Takeshita K 1993 Sugar chains of serum transferrin from patients with carbohydrate deficient glycoprotein syndrome. Evidence of asparagine $N$-linked oligosaccharide transfer deficiency. J Biol Chem 268:5783-5789 